\title{
INFÂNCIAS MONOTÔNICAS: representações da alteridade na escrita de pesquisa
}

\author{
MONOTONIC CHILDHOODS: representations of otherness \\ in research writing
}

\author{
Denise Marcos Bussoletti* \\ Pedrinho Arcides Guareschi ${ }^{* * *}$
}

\begin{abstract}
Resumo
Este artigo é parte resultante da tese de doutorado intitulada "Infâncias Monotônicas - uma rapsódia da Esperança". Insere-se na perspectiva de um estudo psicossocial e cultural crítico e objetiva discutir acerca das representações do outro na escrita de pesquisa, elegendo a infância como um lugar alegórico e reflexivo. Contempla, pela análise, os desenhos e os poemas das crianças do gueto de Terezin no período da Segunda Guerra Mundial. Toma como base a Teoria das Representações Sociais, de Serge Moscovici, na interlocução constante com outras teorias e campos de conhecimento, utilizando especialmente as contribuições de Walter Benjamin e Mikhail Bakhtin. Conclui sustentando a tese que concebe a poética como um dos eixos tradutores das culturas das infâncias.

Palavras-chave: Representações Sociais. Infâncias. Alteridade.
\end{abstract}

\begin{abstract}
This paper is part of a doctoral thesis entitled "Monotonic childhoods - a rhapsody of hope". It follows the perspective of a critical psychosocial and cultural study, and aims at discussing the other's representation in research writing, electing childhood as an allegorical and reflective place. It takes into consideration, by means of analysis, the drawings and poems of children from the Terezin ghetto during the Second World War. The work is mostly based on Serge Moscovici's Social Representation Theory, but it is also in constant dialogue with other theories and knowledge fields, especially Walter Benjamin's and Mikhail Bakhtin's contributions. At the end, the paper supports the thesis that conceives poetics as one of the translation axes of childhood cultures.
\end{abstract}

Keywords: Social representations. Childhoods. Otherness.

\section{A Canção dos Pássaros: prelúdio}

\author{
A Canção dos Pássaros \\ Quem segue sentado em seu ninho, \\ não conhece o que é o mundo. \\ não conhece o que todos os pássaros sabem, \\ nem sabe sobre o que eu quero cantar, \\ que o mundo está cheio de belezas. \\ Quando a luz da manhã chega a terra, \\ e gotas de orvalho brilham no pasto, \\ um melro canta sobre o arbusto, \\ saudando o amanhecer, \\ então sei que é maravilhoso viver. \\ Olha, trata de abrir teu coração à beleza, \\ vê os bosques um dia, \\ e ali faz uma coroa com tuas lembranças. \\ Então, se as lágrimas enturvarem teu caminho, \\ saberás que é maravilhoso viver.
}

(Autor desconhecido - Criança de Terezin)

Este texto objetiva tratar sobre as representações do Outro na escrita de pesquisa, utilizando a infância como representação dessa alteridade. No entanto, para lançar-se no desafio de escrever de um lugar onde a infância ocupa um espaço de protagonismo, é necessário, antes de qualquer coisa, pluralizar sentidos, na busca de um diapasão que permita afinar os instrumentos e identificar possíveis gêneros ${ }^{1}$ de forma a possibilitar uma representação ou interpretação das produções infantis, como a Canção dos Pássaros destacada acima, com a maior fidelidade possível.

\footnotetext{
"Este artigo é parte integrante das reflexões realizadas na tese de doutorado "Infâncias Monotônicas - uma rapsódia da Esperança - Estudo psicossocial cultural crítico sobre as representações do Outro na escrita de pesquisa" (BUSSOLETTI, 2007), orientada pelo professor Ph. D. Pedrinho Guareschi.

" Professora da Faculdade de Educação da Universidade Federal de Pelotas. E-mail: denisebussoletti@gmail.com

*** Professor convidado da Universidade Federal do Rio Grande do Sul (UFRGS) e da Universidade Federal de Ciências da Saúde de Porto Alegre (UFCSPA). E-mail: pedrinho.guareschi@ufrgs.br

1 Partindo da concepção bakhtiniana o querer-dizer de um sujeito se realiza, com maior ou menor eficácia, pela escolha de um gênero. Os gêneros como falas sociais são re-criações que possibilitam compreensões socialmente partilhadas. Em "Problemas da Poética de Dostoievski", Bakhtin utiliza o termo "diapasão lexical" para chamar a atenção para as formas de fala comuns a uma determinada época e meio. Assim, ao falante são dados, para além da língua nacional, os gêneros do discurso, que são tão indispensáveis quanto as formas da língua. (BAKHTIN, 2005).
} 
A palavra interpretar, aliada ao conceito de representações sociais $^{22}$, central neste trabalho, possibilita uma incursão textual-musical por onde a escrita busca se aproximar da execução de uma partitura e, pelo desempenho, efetuar em texto essa metafórica proximidade. Uma passagem pela infância que necessita do coro de muitas e diferentes vozes, fazendo da polifonia um princípio e das dissonâncias um contraste inalienável à complexidade do tema abordado ${ }^{3}$.

Alertamos, assim, que uma música é propensa a atravessar este texto, e será a música o seu fio condutor. Revelamos, também, um lugar de onde a escuta da Canção dos Pássaros se fez, inicialmente, não só pela canção por si mesma, mas fundamentalmente pelo que ela nos inspira: a crença de que é possível criar condições para percorrer caminhos por mais árduos que sejam desde que orientados por essa força que a arte e a infância conferem à vida.

Cumpre dizer que o autor desconhecido da Canção dos Pássaros era uma criança pertencente ao gueto de Terezin, cuja produção foi realizada durante a Segunda Guerra Mundial. Trataremos desses produtos infantis neste artigo, através dos desenhos e dos poemas de algumas dessas crianças; buscaremos as representações que a alteridade através da infância nos possibilita e o que virá a seguir é parte dos nossos esforços de sistematizações acerca da temática perseguida. Para cada escala da escrita deste artigo estão previstas possibilidades, paisagens, passagens que traçarão o espaço e o tempo em que se configura o pesquisar que, aliando as metáforas musicais, compõem o seguinte percurso: Prelúdio, tópico em que a introdução se faz através deste movimento inicial nominado "A canção dos Pássaros", e que pretende anunciar o destino e o objetivo da escrita em perspectiva. Posteriormente, abordaremos "As representações do Outro pela Infância”, considerando que representar é também re-apresentar; portanto, por um lado é cópia e, por outro lado, interpretação da realidade, "um misto de pré-ciência, ainda nos estágios de descrição do real, e de teatro, em que atores criam um mundo imaginário, reflexo também do mundo em que vivemos - um exemplo como queria Wittgenstein, do poder da linguagem de criar o mundo" (SPINK, 1993, p. 7).

\footnotetext{
2 Insiro este trabalho na área dos estudos em representações sociais. Considerada como um marco nos estudos psicossociais, a teoria das representações sociais foi apresentada por Serge Moscovici em 1961, através de sua obra consagrada La psychanalyse, son image et son public, cuja pretensão inicial era a de demonstrar como se dá a formação de "um novo senso comum" a partir de modelos científicos propostos.

${ }^{3}$ Esse conceito de polifonia de matriz bakhtiniana, e outros que foram selecionados neste estudo, como o de vozes, dialogia, exotopia, cronotopos, estilo, autoria, gênero, entre outros, buscam uma articulação com os estudos psicossociais que enfrentam o caráter dialógico da linguagem.
}

Pelos caminhos das representações do outro, a próxima tentativa que este texto fará, em andamento moderado denominado andante, será a de re-apresentar os horizontes de uma proposta de abordagem ético-estética. Transitará pela linguagem e pela proposta de buscar as representações da alteridade na escrita de pesquisa pela infância, estabelecendo os contornos da busca da "pura expressão". Nesse movimento, postula a defesa de uma ciência crítica que busque apreender a complexidade da experiência humana numa relação dialógica ${ }^{4}$ com a arte e com o sentimento estético. A crença é a de que a ciência pode e deve ser cúmplice de outros conhecimentos discursivos, contrapondo-se a toda e qualquer demarcação rígida em suas fronteiras. Para, além disso, e na mesma perspectiva, este momento do texto tentará explicitar a tese de que a busca da pura expressão, da autoria e da criação em pesquisa se constroem no tensionamento entre as representações do Outro no e pelo/a autor/a; só assim o criador/a - autor/a pode inscrever sua própria voz e seu silêncio.

Num outro movimento textual-musical, como dissonâncias questionadas, "As crianças de Terezín" incursionará pela "cidade labiríntica" benjaminiana, através dos desenhos e de alguns poemas escritos pelas crianças de Terezín, extraídos do Catálogo publicado pelo Museu Judaico de Praga, na versão espanhola intitulada No he visto mariposas por aqui ${ }^{5}$. Esse catálogo faz parte da mostra itinerante que viaja pelo mundo mostrando os poemas e os desenhos das crianças judias que viveram sob o nazismo durante a Segunda Guerra Mundial (1939-1945). Aproveitamos os documentos dessa experiência como narrativas expostas na mostra realizada no Brasil entre os dias 19 de abril e 09 de maio de 2004. Nesses documentos as crianças demonstram o que pintavam e escreviam sobre seus sentimentos e experiências. Os desenhos e os poemas das crianças nessa perspectiva metodológica foram assim compreendidos enquanto objetos representacionais, testemunhos de uma cultura, formas simbólicas que permitem a apreensão da expressão geracional distinta das culturas infantis.

O trabalho geralmente era realizado sob a orientação da artista Friedl Dicker-Brandejs. Os desenhos, na maioria, eram de crianças entre 10 e 15 anos de idade, e a atividade era realizada através de círculos que tematizavam a vida em Terezín. Os poemas, que fazem parte da mostra, foram encontrados em revistas que eram publicadas dentro do gueto, acompanhados muitas vezes por desenhos.

\footnotetext{
${ }^{4}$ Dialogia é o caráter da interação verbal enquanto categoria básica da concepção de linguagem em Bakhtin, em que toda enunciação faz parte de um processo de comunicação interminável.

${ }^{5}$ Para fins da edição deste artigo os desenhos originalmente coloridos serão apresentados em versão preto e branco.
} 
Utilizamos esse material explorando as dimensões ética e estética como possibilidades de investigação, expressão e análise efetiva. Postulamos que se a escrita de pesquisa com crianças objetivar assumir uma perspectiva "tradutora", "intérprete" ou "narradora" das infâncias, ela deve aproximar-se do caráter ficcional inerente à gramática das culturas infantis. Tentando apreender as gramáticas das culturas da infância, exploramos a hipótese formulada por Sarmento (2004) sobre as afinidades que existem entre os princípios lógicos alterados das culturas da infância e a linguagem poética (imagem e palavra imagética), propondo eleger a poética como um outro pilar das gramáticas das culturas da infância.

Por fim, alguma conclusão é pretendida, porém nos moldes do necessário caráter de incluso ao texto em perspectiva. Aponta para a atitude alerta e de busca constante pela escrita de pesquisa. $\mathrm{Na}$ pauta, apresenta-se a sinfonia monotônica como tentativa de conceito ou síntese das notas perseguidas.

\section{As representações do Outro pela Infância - Andante}

Na procura da palavra instantânea, ou da pura expressão acatando o enfrentamento de questões epistemológicas polêmicas nas Ciências Humanas e Sociais, postulamos que "epistemologia significa conhecer a diferença" (HARAWAY, 2000). Compreendemos também que polemizar é possibilitar fazer "emergir diferenças insubmissas" (GERALDI, 2003), constituindo-se num dos caminhos para debater um ponto de vista que supõe um outro olhar no campo de pesquisa. Esse olhar assume o desafio de transitar para além dos paradigmas ditos "cientificistas", pautados pela razão instrumental, na perspectiva de construção de "uma abordagem ética e estética da realidade", onde os limites da racionalidade técnica possam ser forjados pela inclusão das paixões e das utopias, tão demasiadamente humanas, portanto imprescindíveis a um conhecimento que se reivindique vivo (SOUZA, 1994).

Essa articulação entre ética e criação busca em sua origem estabelecer o diálogo entre Bakhtin - considerado como o fundador da discursividade e construtor da ideia de dialogismo ou polifonia no campo da teoria literária e da filosofia da linguagem - e a teoria das representações sociais proposta por Moscovoci. Do âmbito que esse conceito nos remete, podemos compreender que:

Representar significa, a uma vez e ao mesmo tempo, trazer presentes as coisas ausentes e apresentar coisas de tal modo que satisfaçam as condições de uma coerência argumentativa, de uma racionalidade e da integridade normativa do grupo. [...] Conseqüentemente, o status dos fenômenos da representação social é o de um status simbólico: estabelecendo um vínculo, construindo uma imagem, evocando, dizendo e fazendo com que se fale, partilhando um significado através de algumas proposições transmissíveis e, no melhor dos casos, sintetizando em um clichê que se torna um emblema. (MOSCOVICI, 2003, p. 216-217).

Seguimos assim explorando e tomando como centralidade o campo inaugurado com a teoria das representações sociais por Moscovici, procurando através da problemática da alteridade em seus possíveis desdobramentos contribuir com a tarefa constante de renovação e atualização teórica e metodológica. Partimos das interlocuções que a Psicologia Social vem interpretando como necessidade, pois, como sugere Denise Jodelet, "a reflexão sobre a alteridade deságua sobre todo um campo a desbravar: os dilaceramentos e fendas que o trabalho de construção social da realidade abre na experiência humana, as destruições que a negatividade performante das representações sociais acarreta" (JODELET, 1998, p.66).

Pensamos que escrever sobre o humano, hoje, requer um redirecionamento na pesquisa, adotando a hipótese primeira de que sem o reconhecimento da alteridade não há sequer objeto de pesquisa. É no incessante diálogo do pesquisador com o Outro, seja pela análise, pela relação, pelo trabalho de campo e/ou pela escrita, que a questão da alteridade se faz presente, mostrando aspectos da problematização da designação do Outro, da condição de alteridade no texto de pesquisa.

Um dos elementos chaves da teoria da linguagem de Bakhtin é a palavra do Outro, de um Outro que não se opõe como categoria fechada ao 'eu'. Na linguagem viva, cada palavra é como que o resultado de uma relação de força entre o eu e o outro, numa tensão que se manifesta em todos os níveis, no 'material', na 'forma', no 'conteúdo', num todo inseparável. Nossas palavras não são 'nossas', apenas; elas nascem, vivem e morrem na fronteira do nosso mundo e do mundo alheio; elas são respostas explícitas ou implícitas às palavras do outro, elas só se iluminam no poderoso pano de fundo das mil vozes que nos rodeiam. (TEZZA, 1988, p. 55).

$\mathrm{Na}$ teoria da linguagem bakhtiniana, compreender a voz não é simplesmente decodificar mecanicamente a voz de um Outro, mas sim tomar a linguagem como viva, a palavra como viva.

Compreender é um processo ativo; é adentrar um mundo estrangeiro, é num momento ver como o outro vê, é viajar por todas as nuances intencionais daquele que nos fala, e fazer das palavras dele a nossa palavra, já no terreno das nossas intenções e dos nossos pontos de vista - num certo sentido, toda palavra viva é impura, dupla, dialógica. $\mathrm{Na}$ 
expressão de Bakhtin, só há Adão mítico, diante de um mundo virgem, poderia evitar a dialogização. (TEZZA, 1988, p. 55).

Adotar uma abordagem dialógica não significa a adoção de um método ou de um modo de escrita, mas implica reconhecer na teoria bakhtiniana uma das condições de possibilidade que tornam possível o exercício do interrogar, do abrir vias de investigação e de estabelecer uma proposta de análise. Essa proposta de análise carrega consigo a hipótese básica de que o pensar e o fazer conhecimento em Ciências Humanas requerem incluir o Outro, como questão da alteridade implícita.

Guareschi chama a atenção para o fato de que, principalmente no campo da Psicologia Social, os temas ligados à ética, à justiça e à alteridade são pouco discutidos. Reconhecendo a dificuldade dada à relativa complexidade e à dificuldade na aproximação da questão, e como partilho com o autor a constatação de que não há ação humana que não pressuponha a ética, coloco-me na intenção de dar visibilidade à dimensão indissociável da ética e da alteridade na pesquisa, e de reconhecê-la, fazendo dela a centralidade reflexiva.

Creio que à medida que começo a pensar o ser humano a partir das relações, uma nova dimensão surge na minha prática: a dimensão da alteridade. Damo-nos conta de que o outro é alguém essencial em nossa existência no nosso próprio agir. Ele se torna alguém necessário, alguém imprescindível para a própria compreensão de mim mesmo. (GUARESCHI, 1998, p. 160-161).

Nessa perspectiva, acatar a dimensão da alteridade significa, como também compreende Arruda (1998), que as representações não servem apenas à integração do Outro como um estranho, mas também à transformação do que é familiar. Estranhar o familiar é retirar a representação de sua ancoragem no terreno exclusivo do passado e buscar o novo, aquilo que reordenará (mesmo que pela desordem) o familiar, não só pelo objeto, mas pelo contexto da representação, permitindo uma aproximação mais ampla tanto dos pensamentos como dos afetos, ultrapassando o real e o racional na sua explicação.

No movimento conflitivo entre a familiarização e o estranhamento assumimos a possibilidade de fazer deste exercício de escrita um momento de uma viagem ou de um exílio voluntário. Ao mesmo tempo em que acolhemos, somos acolhidos por aquilo que nos é estranho - nos movimentar em direção ao território do Outro -. pois admitimos que é só no duplo movimento de abandono e de reconhecimento que a alteridade pode ser traduzida e transmitida pela pesquisa. Ou ainda, por Kristeva,

[...] estranhamente o estrangeiro habita em nós: ele é a face oculta da nossa identidade, o espaço que arruína a nossa morada, o tempo em que se afun- dam o entendimento e a simpatia. Por reconhecê-lo em nós poupamo-nos de ter que detestá-lo em si mesmo. Sintoma que torna o "nós" precisamente problemático, talvez impossível, o estrangeiro começa quando surge a consciência de minha diferença e termina quando nos reconhecemos todos estrangeiros, rebeldes aos vínculos e às comunidades. (KRISTEVA, 1994, p. 10).

Assumindo, assim, o desafio de buscar fazer pesquisa pelos caminhos da diversidade, articulando ética, estética e criação, acredito estar sendo fiel ao princípio do dialogismo bakhtiniano, no qual todas as vozes interessam, todas as vozes podem e devem ser ouvidas, pois dialogar não significa substituir ou justapor locutores, mas interagir sem impor de forma dogmática uma voz em detrimento das demais, nem relativizar de forma que todas as vozes coexistam acriticamente, mas sim buscar "a síntese dialética das vozes contrárias" (FARACCO, 1988, p. 24).

No entanto, existe uma impossibilidade de coincidência entre os olhares do Eu e do Outro. Bakhtin (2003) propõe o conceito de excedente estético para compreender a dimensão ética dessa atividade estética. Um "excedente estético" deve estar aliado a um ato ético para que a atividade estética se verifique e as soluções tornem-se possíveis.

Buscar descortinar um mundo histórico através dessa relação que também é estética procura revelar a imagem de um tempo ético da narração. Neste projeto ético-estético identifico aquilo que Levinas (2000) denuncia como sendo o tempo em que o mundo aparece como se estivesse entre parênteses, linguagens aprendidas e indecifradas, parentéticas, que permitem efetuar uma "externalidade do interior" fazendo da subjetividade, do sujeito histórico e narrativo uma referência para o outro, que, por sua vez, constitui a interioridade do próprio sujeito. É, fundamentalmente, essa "arte mágica" de "ver a interioridade a partir do exterior" que localiza esta proposta de escrita/investigação na perspectiva de viagem ao território do estranho, buscando o encontro, ou realizando a busca da fronteira onde se reafirma o sujeito e a sua identidade cultural e social (BHABHA, 1998)

Quando a visibilidade histórica já se apagou, quando o presente do indicativo do testemunho perde o poder de capturar, aí os deslocamentos da memória e as indireções da arte nos oferecem a imagem da nossa sobrevivência psíquica. Viver no mundo estranho, encontrar suas ambivalências e ambigüidades encenadas na casa da ficção, ou encontrar sua separação e divisão representadas na obra de arte, é também afirmar um profundo desejo de solidariedade social [...]. (BHABHA, 1998, p. 42).

Buscar o Outro é assumir um lugar de responsabilidade. No entanto, a responsabilidade com o Outro, continuando com Levinas, não é um simples 
atributo da subjetividade, como se fosse anterior à relação ética. A subjetividade não é um "para si" e sim, inicialmente, um "para o Outro". Não se trata, é claro, de uma proximidade espacial, geográfica, mas de uma proximidade que "se aproxima de mim enquanto eu me sinto", e só esse aproximar sobre o que eu sou é que me permite reconhecer e ser responsável pelo Outro.

Soy yo quien suporta al otro, quien es responsable de él. Así, se ve que en el sujeto humano, al mismo tiempo que una sujeción total, se manifiesta mi primogenitura. Mi responsabilidad es intransferible, nadie podría reemplazarme. De hecho, se trata de decir la identidad misma del yo humano a partir de la responsabilidad, es decir, a partir de esa posición o de esa deposición del yo soberano en la conciencia de sí, deposición que, precisamente, es su responsabilidad para con el otro. La responsabilidad es lo que, de manera exclusiva, me incube y que humanamente, no puedo rechazar. Esa carga es una suprema dignidad del único. Yo no intercambiable, soy yo en la sola medida en que soy responsable. Yo puedo sustituir a todos, pero nadie puede sustituirme a mí. Tal es mi identidad inalienable de sujeto. En ese sentido preciso es en el que Dostoiveski dice: "Todos somos responsables de todo y de todos ante todos, y yo más que todos los otros." (LEVINAS, 2000, p. 85).

Se todos somos responsáveis, e eu mais que todos, em tempos em "que o belo se vê tão mal", representar o Outro através da escrita da infância e da escrita de pesquisa é confessar que: "[...] momentos como esses jamais deveriam passar ou ser esquecidos: exigiam um prolongamento para que pudessem continuar a agitar-se; uma melodia; o CANTO" (HANDKE, 1992, p. 90). Pela canção dos pássaros o Outro, a criança, enquanto voz, enquanto esperança, retoma. Quais seriam os desafios?

Para compreender o que a infância é, o que ela conta, ou o que ela ainda pode ser, é necessário, pois, tentar reencontrar o que o mundo adulto pode ainda experimentar pela infância, algo como pequenas epifanias, que fazem o "já visto" aparecer como diferente. Nesse processo uma palavra pode assumir a força repentina de tornar um instante vivo. Assim, a paisagem se altera e tudo poderá aparecer com uma nitidez de novidade. É a palavra que, pela criança, acusa a sua presença e transforma todo o tempo na "simultaneidade cristalina" ${ }^{\text {de um "agora". }}$

\footnotetext{
${ }^{6}$ Utilizamos a expressão que Benjamin utilizou no Drama Barroco Alemão. A representação de uma ideia é monádica, a ideia é uma mônada, e nessa perspectiva cada ideia contém a imagem do mundo (BENJAMIN, 1984).

${ }^{7}$ Benjamin distingue o tempo controlado pelos relógios do "tempo homogêneo e vazio". Neste, os acontecimentos caem dentro dele, do tempo pontuado pelo calendário, onde os "dias de recordação, as coisas são relembradas e tornadas atuais". O tempo histórico não é aquele das badaladas indiferentes e regulares do relógio, mas sim o momento de pausa, quando a interpretação do passado assume-se como uma construção e a história, como presente.
}

Nessa perspectiva, apreender a infância, nas pistas de Larrosa, implica reconhecer na infância esse Outro que está entre nós. Não um Outro como uma mera tela de projeções dos nossos fracassos ou incapacidades de dizer sobre o que a infância é, mas um Outro que justamente remete à dissolução de nossas certezas, tanto as certezas de mundo como as de nós próprios.

Na medida em que encarna o surgimento da alteridade, a infância nunca é o que sabemos (é o outro dos nossos saberes), mas por outro lado, é portadora de uma verdade à qual devemos nos colocar à disposição de escutar; nunca é apreendido pelo nosso poder (é o outro que não pode ser submetido, mas ao mesmo tempo requer nossa iniciativa; nunca está no lugar que a ela reservamos (é o outro que não pode ser abarcado), mas devemos abrir um lugar para recebê-la. Isso é a experiência da criança como um outro: o encontro de uma verdade que não aceita a medida de nosso saber, com uma demanda de iniciativa, que não aceita a medida de nosso poder, e com uma exigência de hospitalidade que não aceite a medida de nossa casa. [...] Trata-se aqui, então de devolver à infância a sua presença enigmática e de encontrar a medida de nossa responsabilidade pela resposta que esse enigma leva consigo. (LARROSA, 2000, p. 186).

Questionar nossos saberes sobre a infância é buscar através dela o que Agamben (1989) denomina como a "pura expressão". Algo como uma "experiência original pura", uma "infância da experiência". O problema é como fazer para encontrar essa "pura expressão" e relacionar essa "infância considerada como experiência" com a linguagem.

Eleger a infância se coloca, assim, como uma alternativa de pesquisa a um mundo adulto sensorialmente empobrecido. Através de Benjamim, acredito que as crianças são capazes de decifrar o "rosto do mundo das coisas", dar visibilidade e riqueza a tudo aquilo que, abandonado pelo mundo adulto, nos provoca a meditar sobre esse "canteiro de obras", sobre esse rótulo de insensato que as "rançosas especulações" acadêmicas têm outorgado às produções infantis, ou que por um reducionismo especulativo qualquer nos impeçam de compreender que "a terra está cheia de objetos" e que a atenção e a ação das crianças sobre estes pode renovar, criar e imprimir novos significados. (BENJAMIN, 2002).

Pelas palavras e pelos contornos da beleza e da ética, da incompletude humana, pela busca da pura expressão - eis o desafio da pesquisa: quem dera fosse ousadia! - deixemos agora que as crianças de Terezin mais nos digam. 


\section{As crianças de Terezín - Dissonâncias?}

Situada a uns $60 \mathrm{Km}$ de Praga, Terezin é uma cidade que, nos anos de guerra, foi uma das paradas onde os judeus (entre outros grupos) de toda a Europa foram levados para depois serem transportados aos campos de concentração. Estima-se que 15.000 crianças chegaram ao gueto e destas sobreviveram apenas 100. Passaram-se muitos anos desse terrível momento da história humana, e as cinzas do holocausto produziram feridas profundas na humanidade. Das crianças de Terezín restaram seus desenhos e seus poemas, fragmentos e narrativas que nos permitem encontrar parte de sua história.

Mèredieu (1979) fez um estudo comparando desenhos de crianças que haviam passado por situações de guerra e desenhos realizados por crianças em campos de concentração. Verificou que esses desenhos constituem uma mistura - uma exata mistura - da tragicidade dos acontecimentos e dos elementos que fazem parte de seu vocabulário habitual: o sol, as flores, as casas. Cabe dizer que é entre o trágico e o belo, ou na tragicidade da beleza, que os sons, as cores, as dores e, sobretudo, a esperança de uma época são representados, em traços e tintas, pelas crianças.

Seguindo através de Benjamin os labirintos da história encontramos Terezin, uma cidade cujos habitantes foram condenados à morte, uma cidade que foi assim descrita:

Terezín, fue en los años de la guerra una ciudad de hambre y de miedo. Lejos de allí, en algún lugar de Berlín, hombres uniformados se reunieron y decidieron exterminar a todos los judíos de Europa. Estaban acostumbrados a hacerlo todo con calculadora y fría pasión homicida y así trazaron los planes, designaron países, lugares, términos y también paradas en el camino hacia la muerte. Una de estas paradas era Terezín, que debía ser una parada modelo adonde podrían llevar a los extranjeros para mostrársela y que fue llamada ghetto. Primero llevaron a Terezín a los judíos de bohemia y Moravia, y después de toda Europa. $Y$ desde allí eran transportados al Este, a las cámaras de gas y a los hornos [...]. (WEIL, 1996, p. 9).

Entretanto, numa outra paisagem pareciam também habitar as crianças de Terezín; num espaço em que a criança-alegorista, através de sua linguagem secreta, vai mostrando como os sonhos foram sendo perdidos pelas "30 000 almas" que ali dormiam. Na perspectiva benjaminiana, a criança alegorista é aquela que, diferente do poeta - e como o velho -, não esquece.

Cada lembrança é um fragmento, já que a história contínua é uma ilusão. Este fragmento é a cristalização instantânea no devir da infância; é um microcosmo que contém em miniatura, não apenas seu destino posterior, mas, sobretudo, a promessa utópica de homens melhores, de um mundo feliz, no qual o homem, a natureza e as coisas, liberadas da 'corvéia de serem úteis' viveriam reconciliadas sem a marca da reconciliação. A memória determina o olhar da criança-alegorista a fim de revisitar essa outra figura do passado [...]. (MATOS, 1995, p. 89).

Figura 1 - Eva Wollsterinerová, 24/01/1931 - 23/01/1944

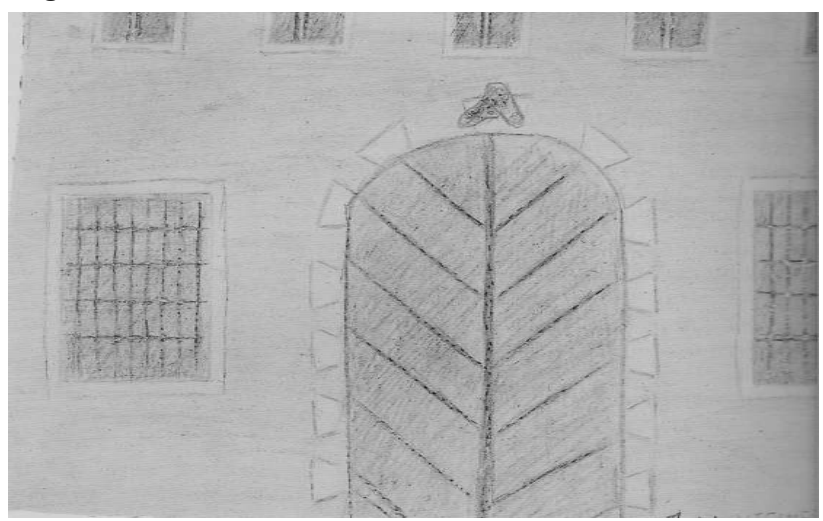

Fonte: @ Museu Judaico de Praga

Terezín

Esta mugre em las súcias paredes, Alambradas a todo alrededor, Y 30000 almas que duermen Que alguna vez despertarán Y verán su propia sangre derramada Estas 30000 almas que duermen allá Entre los árboles despertarán, Abrirán sus ojos

Y como verán muchas cosas se dormirán de nuevo.

(Hachenburg, Hanus. 12/07/1929 - 10/12/1944)

As crianças em Terezin viam tudo o que os adultos viam, mas viam também o que os adultos não queriam ver: "a beleza por trás das portas da cidade".

[...] verdes prados y colinas azuladas la cinta de la carretera perdiéndose en la distancia con su señal imaginaria indicando "Praga", los animales, pájaros, mariposas, - todo estaba al otro lado de las murallas y podían verlo desde lejos, desde las ventanas del cuartel y desde las vallas fortificadas adonde algunas veces le dejaban ir. Veían, además cosas que los adultos no podían ver - princesas con diademas de diamantes, brujas y magos malvados, payasos y escarabajos con caras humanas, el país de la felicidad donde la entrada costaba 1 corona, y donde había de todo - pasteles, dulces, un cerdito trinchado con un tenedor, ríos de leche y limonada. Veían también sus habitaciones de antaño, con cortinas en las ventanas y el gato con su platito de leche [...]. (WEIL, 1996, p. 10). 
A concepção da história como um labirinto e da cidade labiríntica nesse "lugar de passagem" que foi Terezin resgata a viagem da criança no sentido contrário ao da morte. Benjamin afirma que os sentidos da história são melhor compreendidos nos momentos de agonia e morte, e que contra a repetição somente se pode contar com o "princípio-esperança".

Em cada época, é preciso arrancar a tradição ao conformismo, que quer apoderar-se dela [...] $\mathrm{O}$ dom de despertar no passado as centelhas da esperança é privilégio exclusivo do historiador convencido de que também os mortos não estarão em segurança se o inimigo vencer. E esse inimigo não tem cessado de vencer. (BENJAMIN, 1994, p. 224225).

A criança faz da ruína uma esperança. Numa cidade em que a morte era um fim anunciado, expressa o "princípio-esperança".

Algún Dia

Algún día, algún día llegará Algún día aparecerá el consuelo Algún día florecerá la esperanza

Algún día se aliviarán las penas

Algún día se romperá el cántaro de lágrimas Algún día se le dirá a la muerte "Ya calla".

Al fin vendrá un verdadero amanecer

El agua se convertirá en vivo

Algún día dejaremos de llorar

Algún día se curarán nuestras heridas

Algún día José, algún día

Dios quitará las cadenas de esclavitud.

Algún día Herodes, loco de miedo

Morirá

Y David el pastor

En púrpura real llegará

El que una vez sufrió

El odio y la crueldad del Rey Saúl.

Algún día terminarán las penas,

Esta vivencia triste

Algún día llegará el salvador

Con todo su poder

Algún día, si Dios lo quiere

Seremos llevados a Canaán.

Algún día florecerá el áloe

La palma dará sus frutos

Algún día cesará la opresión

Terminará nuestra miseria

Algún día entraremos en la casa de Dios

$Y$ todas estas cosas serán realidad.

(Ivo Katz. 11/4/1932 -18/12/1943)

O que há de ser o princípio esperança? $O$ que há de ser a imagem dialética como redenção da tradição dos oprimidos? Benjamin nos mostra com uma 'iluminação', "[...] 'iluminação profana', onde o cotidiano e o mistério conjugam seus poderes, fazendo corpo com o mundo das imagens (Bild). É na imagem que se "telescopiam" o imemorial do passado [...]. Diante do declínio da aura e do longínquo cultural da modernidade como mundo desencanado, talvez se possa construir uma aura inteiramente nova" (MATOS, 1995, p. 92).

Figura 2 - Ruth Gutmannová, 13/04/1930 - 06/10/1944

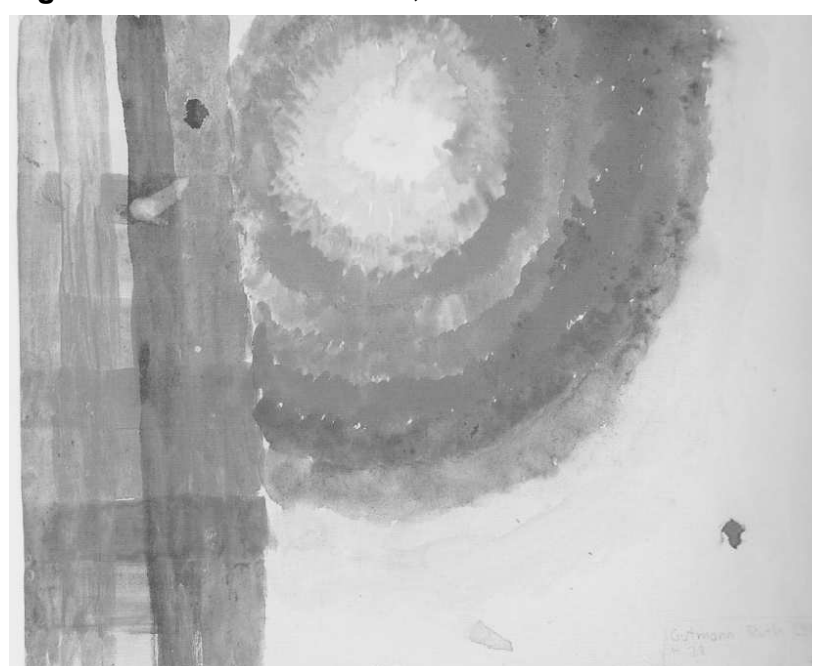

Fonte: @ Museu Judaico de Praga

Aqueles que permaneceram sentados e que pela canção dos pássaros não sabem o que é o mundo medo, o nazismo era sua expressão. O medo e o terror totalitário representam um dos rostos mais terríveis que à humanidade se mostrou. Rostos marcados pelo terror são equivalentes de uma mesma lógica, a que vê um perigo em cada nascimento, pois em cada novo ser humano reside a possibilidade de um novo começo, de que uma nova voz se eleve e possa ser ouvida no mundo. Como essa canção, dirigida justamente àqueles que, não sabendo o que o mundo é, temem e produzem a morte como saída. O infanticídio é a saída totalitária para eliminar do mundo a novidade, a grande ameaça que necessita ser controlada.

Pela canção dos pássaros, o mundo está cheio de belezas; as crianças, como os pássaros, sabem. E, talvez por isso, cantam...

A criança, apesar de tudo, pode nos fazer recuperar o olhar crítico sobre o mal-estar de nossa cultura. Construindo seu universo particular no interior de um universo maior reificado, ela mostra que é capaz de resgatar uma compreensão polifônica do mundo, devolvendo, através do jogo que estabelece na relação com os outros e com as coisas, os múltiplos sentidos que as realidades física e social podem adquirir. É preciso continuar enriquecendo a humanidade com novos mitos e utopias. A criança sabe... (SOUZA, 2000, p. 98). 
Muitos anos se passaram desde a derrota do nazismo, no entanto o seu rosto, que tem muitas faces, ainda se revela. No mundo contemporâneo a morte da infância é cotidianamente inovada. São muitos os seus disfarces, midiáticos, pedagógicos, patológicos, mas o massacre permanece: é necessário hoje, como foi ontem, sufocar o enigma do Outro que a infância representa, e nisso a contemporaneidade também é implacável: a alteridade pela criança é ainda uma ameaça.

A criança precisa do adulto enquanto um 'alter', como um 'outro' diferente, para se constituir como sujeito e se lançar continuamente para além de si mesma em busca de seus projetos e utopias. Por outro lado, a criança também encarna um 'alter' para o adulto. Sendo a infância a humanidade incompleta e inacabada do homem, talvez ela ainda possa nos indicar o que há de mais verdadeiro no pensamento humano: a sua incompletude, mas, também, toda a criação que se prenuncia, ou meIhor, a invenção do possível. Por mais paradoxal que possa parecer e a despeito de todo o desencontro atual entre adultos e crianças, ainda assim é possível enxergar a infância alegoricamente como elemento capaz de desencantar o feitiço da cultura do consumo. Ora, a incapacidade infantil de entender certas palavras e manusear os objetos dando-lhes usos e significações ainda não fixados pela cultura do consumo nos faz lembrar que tanto os objetos como as palavras estão no mundo para serem permanentemente re-significados através de nossas ações. A criança, na sua fragilidade, aponta ao adulto verdades que ele não consegue mais ouvir ou enxergar [..]. (SOUZA, 2000, p. 97).

Figura 3 - Soña Waldsteinová, 28/11/1926 - Sobreviveu

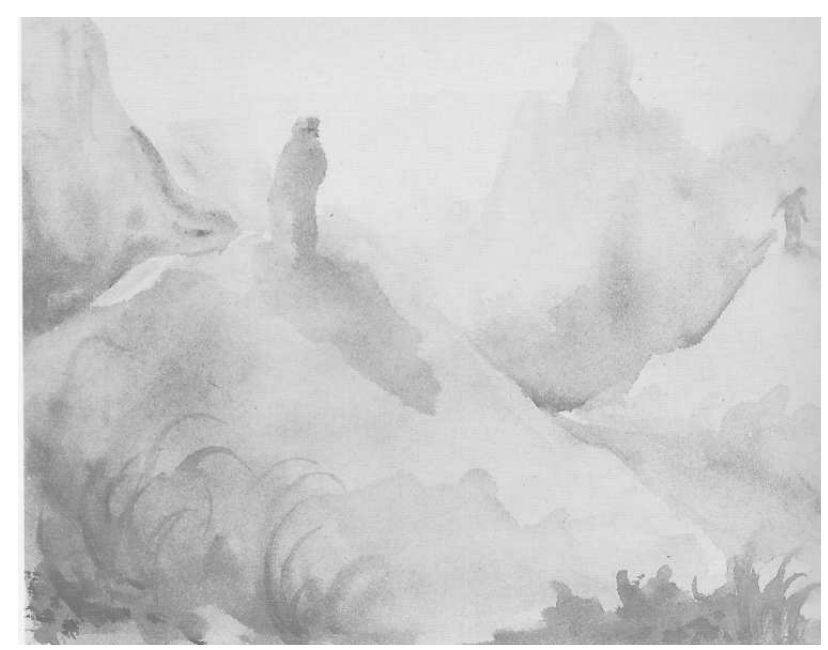

Fonte: () Museu Judaico de Praga.

\section{Para Olga}

Escucha, Ya suena la sirena de la nave Y debemos zarpar
Hacia puertos desconocidos.

Escucha,

Ya es hora.

Navegaremos muy lejos

Los sueños se harán realidad,

¡Qué dulce nombre Marruecos!

Escucha,

Ya es hora.

El viento canya la canción de la lejanía

Mirar sólo el cielo

$Y$ pensar en las violetas.

Escucha,

Ya es hora.

(Alena Synková, 24/09/1929 - sobreviveu)

Invertendo a imagem e buscando suportar a voz da criança, acredito que me coloco em disposição de pesquisa que busca as verdades apontadas pela infância. O que mais podem dizer as crianças de Terezin? Qual gramática nos possibilitaria traduzir sua cultura?

Sarmento, ao interrogar-se sobre o lugar que a criança ocupa, estabelece os marcos de uma geografia necessária, uma geografia que ao questionar o lugar que a contemporaneidade reservou à criança, e considerando, principalmente, o lugar que a(s) criança(s) constrói(oem), defende que:

Ao contrário de todos os medidores de crianças, não nos preocupamos em decretar a inconformidade das crianças contemporâneas com a norma, seja qual ela for. Pelo contrário, defendemos que a diferença radical da infância consiste precisamente em deslocar-se da norma axiológica e gnoseológica constituída pelos adultos, o que faz com que cada criança se insira na sociedade não como um ser estranho, mas como um actor social portador da novidade que é inerente à sua pertença, à geração que dá continuidade e faz nascer o mundo. As crianças, todas as crianças, transportam o peso da sociedade que os adultos Ihes legam, mas fazem-no com a leveza da renovação e o sentido de que tudo é de novo possível. É por isso que o lugar da infância é um entre-lugar [...], o espaço intersticial entre dois modos - o que é consagrado pelos adultos e o que é reinventado nos mundos de vida das crianças - e entre dois tempos - o passado e o futuro. É um lugar, um entre-lugar, socialmente construído, mas existencialmente renovado pela acção colectiva das crianças. Mas um lugar, um entre-lugar, pré-disposto nas suas possibilidades e constrangimentos pela História. É por isso um lugar na História. (SARMENTO, 2004, p. 10).

Tendo como base o estudo sociológico das culturas da infância à autonomia, Sarmento sustenta que "as culturas da infância possuem, antes de mais dimensões relacionais, constituem-se nas interações de pares entre crianças e adultos, estruturando-se nessas relações formas e conteúdos 
representacionais distintos" (SARMENTO, 2004, p. 21). E propõe para o reconhecimento desses traços distintivos o que denomina de "gramática das culturas da infância", que se exprime em várias dimensões, cujo entendimento reproduziremos a seguir:

\begin{abstract}
- Semântica - ou seja, a construção de significados autônomos e a elaboração de processos de referenciação e significação próprios; por exemplo, o "era uma vez" de uma criança não tem uma denotação histórica e temporal, significando o passado, mas remete antes para uma temporalidade recursiva, continuamente convocada ao presente, de tal modo que "era uma vez" é sempre a vez em que é enunciada;
\end{abstract}

- Sintaxe - ou seja, a articulação dos elementos constitutivos da representação, que não se subordinam aos princípios da lógica formal, mas sustentam a possibilidade de contradição do princípio da identidade; o "então eu era o herói' de criança cantado por Chico Buarque de Holanda - exprime bem esta idéia de um ser que se outra no que vê e projecta e, por isso, articula na ordem do discurso o real e o imaginário, o ser o não ser, o estar e o devir, tornados homólogos na sua dupla face;

- Morfologia - ou seja, a especificidade das formas que assumem os elementos constitutivos das culturas da infância: os jogos, os brinquedos, os rituais, mas também os gestos e as palavras; o berlinde do jogo da criança não é apenas um objecto esférico, mas é a peça do jogo, preciosa moeda de troca, o troféu que se obtém ou o artefato mágico que refracta a luz. (SARMENTO, 2004, p. 22-23).

É importante salientar que a conotação exposta não é calcada por um possível reducionismo linguístico, mas faz parte de um conjunto de regras, normas, valores, ritos, disposições, enfim, de elementos que conferem à palavra gramática um outro "ar". Acatamos assim o desafio proposto e assumimos o quanto ainda existe por construir, tanto teórica como epistemologicamente, na perspectiva da "inventariação dos princípios geradores e das regras das culturas da infância". Sarmento propõe quatro "eixos estruturadores" das culturas da infância, a saber: interatividade, ludicidade, fantasia do real e reiteração.

No eixo da interatividade, o pressuposto do mundo da criança como heterogêneo, onde a realidade apresenta-se em suas múltiplas diferenças, faz a identidade da criança.

O mundo da criança é muito heterogêneo, ela está em contacto com várias realidades diferentes, das quais vai aprendendo valores e estratégias que contribuem para a formação da sua identidade pessoal e social. Para isso, contribuem a sua família, as relações escolares, as relações de pares, as relações comunitárias e as actividades pessoais que desempenham, seja na escola ou na participação em tarefas familiares. Esta aprendizagem é eminentemente interactiva; antes de tudo o mais, as crianças aprendem com as outras crianças, nos espaços de partilha comum. (SARMENTO, 2004, p. 23).

O segundo eixo proposto por Sarmento é o da ludicidade, no qual o papel do brinquedo e do brincar é o destaque:

Com efeito, a natureza interativa do brincar das crianças constitui-se como um dos primeiros elementos fundamentais das culturas da infância. O brincar é a condição da aprendizagem e, desde logo, da aprendizagem da sociabilidade. Não espanta, por isso, que o brinquedo acompanhe as crianças nas diversas fases da construção das relações sociais. (SARMENTO, 2004, p. 25-26).

O terceiro eixo é denominado a fantasia do real. Considerando o "mundo do faz de conta" da criança, questiona a expressão "faz de conta" como inapropriada para se referir ao processo da representação infantil. Discorda da dicotomização realidade-fantasia quando atribuída à infância, compreendendo esses universos como intimamente relacionados. Percebe que em relação ao mundo adulto o processo de "imaginação do real" tem sua especificidade.

Nas culturas infantis, todavia, este processo de imaginação do real é fundacional do modo de inteligibilidade. Esta transposição imaginária de situações, pessoas, objectos, ou acontecimentos, esta "não literalidade" [...], está na base da constituição da especificidade dos mundos da criança e é um elemento central da capacidade de resistência que as crianças possuem face às situações mais dolorosas ou ignominiosas da existência. A estrela que transporta para o céu uma pessoa querida, a boneca com que se brinca no meio da desolação e do caos provocado pela guerra ou por um cataclismo natural, a narrativa imaginosa com que se explica um insucesso, uma falha ou até uma ofensa, integram esse modo narrativo de estruturação não literal das condições de existência. É por isso que fazer de conta é processual, permite continuar o jogo da vida em condições aceitáveis para a criança. (SARMENTO, 2004, p. 26-27).

E o quarto e último eixo proposto por Sarmento é o da reiteração. Como complemento da não literalidade, ele apresenta a não linearidade das culturas infantis.

A não literalidade tem o seu complemento na não linearidade temporal. O tempo da criança que é um tempo recursivo, continuamente reinvestido de novas possibilidades, um tempo sem medida, capaz de ser sempre reiniciado e repetido. A criança constrói os seus fluxos de (inter)acção numa cadeia potencialmente infinita, na qual articula continuamente práticas ritualizadas ("agora diz tu, agora sou eu") propostas de continuidades ("e depois... e depois") ou rupturas que se fazem e são logo saturadas ("pronto, não brinco mais contigo"). Nesses fluxos estruturam-se e reestruturam-se as rotinas de acção, estabelecem-se os protocolos de 
comunicação, reforçam-se as regras ritualizadas das brincadeiras e jogos, adquire-se a competência da interacção: trocam-se os pequenos grandes segredos, decodificam-se os sinais cifrados da vida em grupo, estabelecem-se os pactos. E reinventase um tempo habitado à medida dessas rotinas e dessas necessidades de interacção, um tempo continuado onde é possível encontrar o nexo entre o passado da brincadeira que se repete e o futuro da descoberta que se incorpora de novo. (SARMENTO, 2004, p. 28).

Seguindo essa perspectiva e retomando o que até aqui foi apresentado e discutido, estamos em condições de relacionar tudo isso com a nossa tese, que afirma ser a poética um dos pilares de sustentação das "gramáticas das culturas das infâncias" (BUSSOLETTI, 2007).

Uma gramática que pelas infâncias requer lonjuras, o infinito espacial, partitura aérea, inconclusa, indescritível, impronunciável. Uma gramática que resida atrás do pensamento, local onde não existem palavras, palpitam desenhos. Seu terreno? "É-se". Antimelodia de uma harmonia complexa de tudo que é áspero e contrário. Uma gramática que traduz o esforço em trazer o futuro para o "já". Uma gramática que escreva brincando de correr por entre as palavras, com o coração batendo no mundo. Uma gramática que não teme a escuridão da noite total, como brincadeira de "cabracega" pelos holocaustos reproduzidos. Uma gramática que, pela poética, busca insistentemente re-começar a vislumbrar; ou, ainda, busca somente cantar. Luminescências fosforecidas de silêncios e música. Uma gramática sem sinônimos, cuja grafia carrega a potência da palavra liberdade, espalhando a voz e a vez de ser o que os mundos das infâncias sugerem - uma sinfonia.

Figura 4 - Margit Koretzová, 8/4/1933 - 4/10/1944

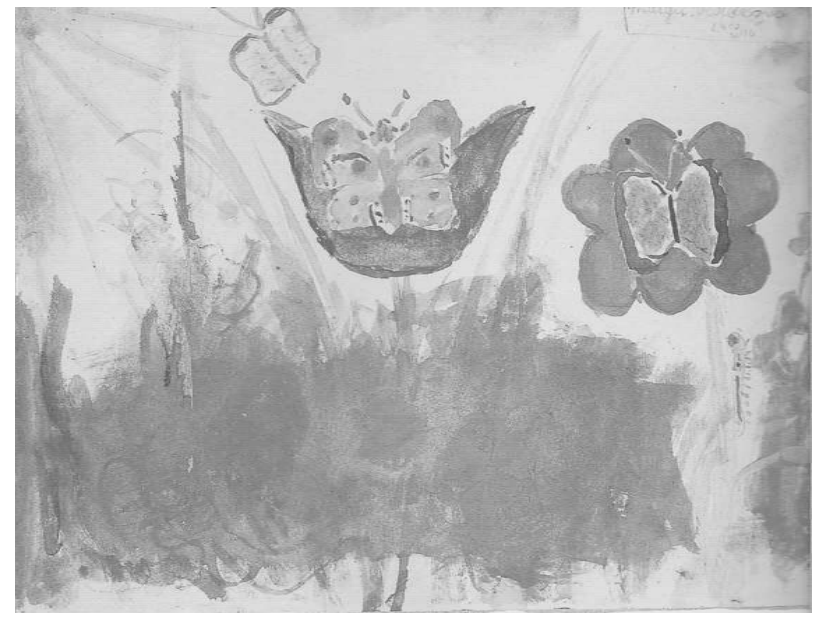

Fonte: (c) Museu Judaico de Praga.

\section{Sinfonia Monotônica - notas perseguidas}

Uma antiga história persa conta sobre a existência de um tocador de flauta, que durante vinte anos entoava uma única e interminável nota. Um dia sua mulher indagou o porquê dessa obstinação, considerando que outros músicos em muito menos tempo executavam várias e belas melodias repletas de notas diferentes. O flautista respondeu: "o que posso fazer, se encontrei a nota que todos os outros procuram?" Esta metáfora do flautista monotônico inspirou, entre outros, o trabalho do pintor Yve Klein, que associava às suas obras monocromáticas performances artísticas nas quais executava uma sinfonia com base numa única e vibrante nota seguida de um prolongado silêncio - uma sinfonia monotônica.

Oportunizando as representações que a metáfora possibilita, propomos para a Canção dos Pássaros uma escuta síntese, aproximando do conceito de infâncias monotônicas uma sinfonia orquestrada por vozes de crianças que, atravessando o tempo, fazem do passado, presente e futuro um acorde único. Antinomias necessárias, tensões representativas de um continuum movimento em que a infância pode ser encontrada, desde que o pesquisador/flautista se permita apreender a reconhecer o que procura.

Diante disso, talvez só nos reste relembrar o que Clarice Lispector uma vez disse: "Já que há de se escrever, que ao menos não esmaguem as palavras nas entrelinhas" (LISPECTOR, 1999, p. 200). Pelas linhas talvez seja prudente afirmar que de forma alguma este texto carrega a pretensão de uma análise maior. Seu propósito é fazer um movimento no sentido de anunciar os caminhos da pesquisa na recuperação da pura expressão, através da problematização das representações do Outro na escrita, sem negar os limites da busca e da dor implícita.

Palavras por vezes rápidas, diante do receio de que os clarões escapem por entre os dedos. $\mathrm{Pa}-$ lavras cuidadosas que temem perder o brilho da beleza que ainda é possível. Palavras partidas por cicatrizes de atmosferas indizíveis. Palavras felizes e palavras tristes. Palavras desassossegadas, pois, entre o sim e o não, são palavras que escolhem o talvez. Palavras independentes que ensinam também o prazer de não saber, de não dizer, e mesmo assim ser, somente o que se pode ser. Palavras inconclusas que amanhecem e anoitecem, mas que tentam permanecer no 'ainda', naquilo que não pode, ou não deve acabar... Nosso sentido de esperança é que pela Canção dos Pássaros nos permitam dizer, novamente com Clarice e pelas crianças, que "atrás do pensamento tem um fundo musical, onde o mais profundo pensamento é um coração batendo" (LISPECTOR, 1998, p. 42). Tem uma sinfonia monotônica, pela pesquisa em nota continuamente perseguida, pautada pelo princípio da esperança 
e pelas reticências que murmuram no para sempre de um inacabado texto acadêmico. Alteridade que reside como escrita no território propositadamente contínuo, sem negar os limites da busca, o desejo e a dor implícita: que as crianças de Terezín e seu canto nunca deixem de ser ouvidos, sinfonia monotônica - contínua procura.

\section{Referências}

AGAMBEN, G. Enfance et Historie. Paris: Payot, 1989.

ARRUDA, A. O ambiente natural e seus habitantes no imaginário brasileiro. In: ARRUDA, A. (Org.). Representando a alteridade. Petrópolis-RJ: Vozes, 1998. p. 17-46.

BAKHTIN, M. Estética da criação verbal. São Paulo: Martins Fontes, 2003.

Problemas da poética de Dostoiévski. Rio de Janeiro: Forense Universitária, 2005.

BENJAMIN, W. O drama barroco alemão. São Paulo: Brasiliense, 1984.

Magia e técnica, arte e política: ensaios sobre literatura e história da cultura. (Obras Escolhidas) v. 1. São Paulo: Brasiliense, 1994.

. Reflexões sobre a criança, o brinquedo e a educação. São Paulo: Duas Cidades, 2002.

BHABHA, H. O local da cultura. Belo Horizonte: Ed. UFMG, 1998.

BUSSOLETTI, D. Infâncias monotônicas - uma rapsódia da esperança - estudo psicossocial cultural crítico sobre as representações do outro na escrita de pesquisa. 2007, 395 f. Tese (Doutorado em Psicologia) - Pontifícia Universidade Católica do Rio Grande do Sul, Porto Alegre, 2007.

FARACCO, C. et al. Uma introdução a Bakhtin. Curitiba: Haiter, 1988.

GERALDI, J. W. A diferença identifica. A desigualdade deforma. Percursos bakhtinianos de construção ética e estética. In: FREITAS, M. T.; JOBIM E SOUZA, S.; KRAMER, S. (Orgs.). Ciências humanas e pesquisa: leituras de Mikhail Bakhtin. São Paulo: Cortez, 2003. p. 39-56.

GUARESCHI, P. Alteridade e relação: uma perspectiva crítica. In: ARRUDA, A. (Org.). Representando alteridade. Petrópolis - RJ: Vozes, 1998. p. 146-161.

HANDKE, P. História de uma criança. São Paulo: Companhia das Letras, 1992.

HARAWAY, D. Antropologia do ciborgue: as vertigens do pós-humano. Belo Horizonte: Autêntica. 2000.
JODELET, D. A alteridade como produto e processo psicossocial. In: ARRUDA, A. (Org.). Representando a alteridade. Petrópolis - RJ: Vozes, 1998. p. 47-67.

KRISTEVA, J. Estrangeiros para nós mesmos. Rio de Janeiro: Rocco, 1994.

LARROSA, J. Pedagogia profana: danças piruetas e mascaradas. Belo Horizonte: Autêntica. 2000.

LEVINAS, E. Ética y infinito. Madrid: A. Machado Livros, S. A, 2000.

LISPECTOR, C. Água viva. Rio de Janeiro: Rocco, 1998. Rocco, 1999.

A descoberta do mundo. Rio de Janeiro: MATOS, O. C. F. Os arcanos do inteiramente outro. São Paulo: Brasiliense, 1995.

MĖREDIEU, F. O desenho infantil. São Paulo: Cultrix, 1979.

MOSCOVICI, S. Representações sociais: investigações em psicologia social. Petrópolis, RJ: Vozes, 2003.

MUSEU JUDAICO DE PRAGA. No he visto mariposas por aqui. Tiskana Flora, 1996.

SARMENTO, M. As Culturas da Infância nas EncruziIhadas da Segunda Modernidade. In: SARMENTO, M.; CERISARA, A. Crianças e miúdos: perspectivas sociopedagógicas da infância e educação. Porto: Edições ASA, 2004. p. 9-35.

SOUZA, S. J. Infância e linguagem: Bakhtin, Vygotsky e Benjamin. Campinas-SP: Papirus, 1994.

Subjetividade em questão: a infância como crítica da cultura. São Paulo: 7 Letras, 2000.

SPINK, M. J. (Org.). O conhecimento no cotidiano. São Paulo: Brasiliense, 1993.

TEZZA, C. Discurso poético e discurso romanesco na teoria de Bakhtin. In: FARACO, C.; et. al. Uma introdução a Bakhtin. Curitiba: Haiter, 1988. p. 51-71.

WEIL, J. Prólogo. In: MUSEO JUDÍO DE PRAGA. No he visto mariposas por aquí. Dibujos y Poemas de los Niños de Terezin. Tiskana Flora, 1996.

Recebido em 13/05/2011

Versão final recebida em 01/08/2011

Aceito em 31/08/2011 